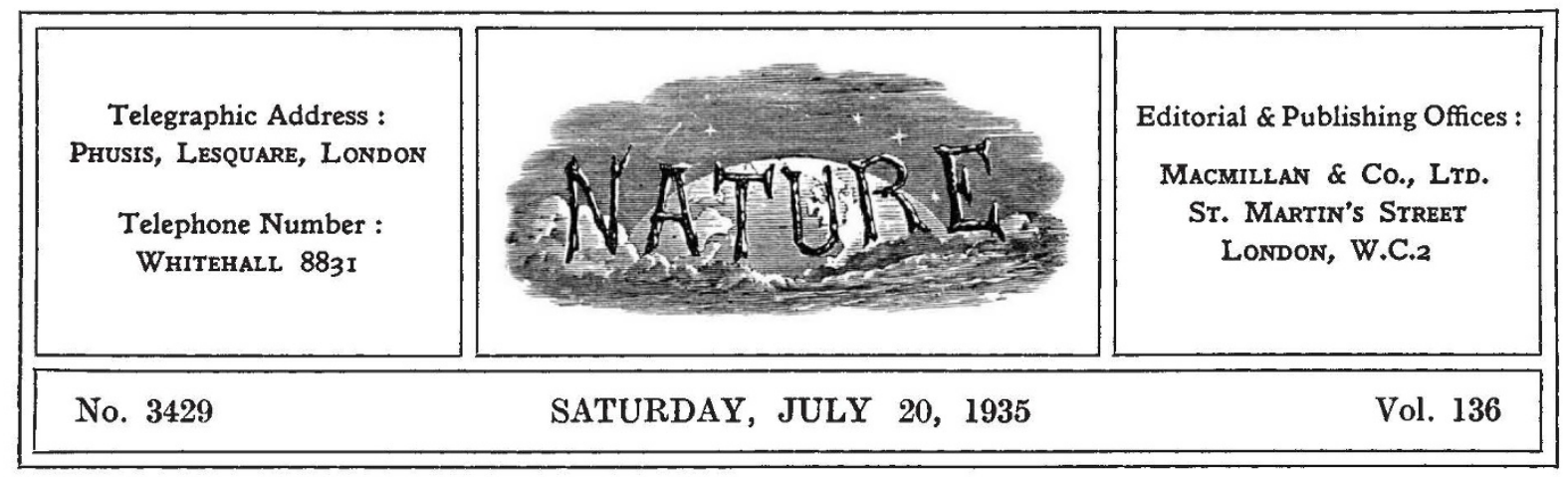

\title{
Chemistry and Citizenship
}

$\mathrm{C}$ HEMISTS, like members of other professional classes, remind themselves from time to time that their vision should extend beyond their professional interests and services into the wider field of the community at large, so that they may bring their specialised knowledge to bear on the problems which their own actions have raised. Not that scientific people are insensible to their duties as intelligent citizens-far from it; but they tend rather to measure their own success or failure in adding to the general store of knowledge, or power, or well-being through spectacles which leave out of focus important considerations none the less real because they are awkward. The physician strives to save life and prolong it; if he succeeds, we applaud him as indeed we should, for has he not contributed to human happiness? But is it, or is it not, the business of the medical man also to see that the effect of an increase in the expectation of life on, say, the vigour of the governing class, or the chance of employment, or the support of the aged, or the use of leisure, is properly examined ? And if he takes up the study himself, since it is clearly impossible for him to refuse medical aid to the sufferer, is he in any better position than his patient to help in the development of a scheme of education and social order suited to the new conditions which he has created?

To judge by one or two lectures which have recently been delivered, chemists are giving attention to the social effects of their own chemistry and industry. Having invented means of producing goods with less labour (although part of the displaced labour has been absorbed in new directions of their own devising), some at least are wondering whether it is not after all their duty to do something rather more definite and vigorous about the social consequences. They are wondering whether the same amount of scientific study given to such disturbances of social equilibrium as is given to the material results of scientific inquiry might not have beneficial results in indicating the best directions of scientific development, as well as in alleviating the troubles which for all our science we have been unable to avoid. Thus Mr. W. M. Ames, in a lecture on "The Chemist and the Community" reported a little time ago in Chemistry and Industry, advocates the scientifically planned State as the logical sequel of the application of science to industry. He wants to establish it without interfering with the freedom of leisure, and without forgetting (as he claims rationalised industry has almost forgotten) that human nature has its failings. He proposes, for one thing, a reduction of working hours, and deplores that such a proposition has been allowed to become a political question instead of being treated as a problem of industrial management. He finds it hard to say whether or not science and human nature would come to blows during the evolution of the scientific State-for various reasons the information to be gleaned from the Russian experiment is not very helpful to othersbut he declares that two million unemployed is a price we cannot afford to pay for the pleasure of muddling along.

Whatever we may think of the means available for its solution, there can be no argument about the problem. Each and every new scientific or industrial advance, whether it brings a new source of employment, a desired or enforced leisure, a longer lease of life, or a quicker way of killing people, sets up ripples and echoes which it is our 
business to trace before they get beyond control and threaten to involve our social fabric in revolution instead of ordered evolution. We cannot stop learning, even to please superior people who have persuaded themselves that too much natural knowledge is antagonistic to their rules for human behaviour. They naturally prefer the latter (which admit of manipulation and alteration) to the former (which does not), and hence they complain that all this knowledge is doing us little good.

Our thesis is that more information about the social relationships of science would help to restore our balance and would lead to better government as well as better science. What, for example, is the proper attitude for scientific workers to take in relation to war? The chemist's part in modern warfare is popularly realised if not understood; and it makes good journalistic copy when normal manufacturing processes become the production of secret explosives, and poison gas exudes from every peaceful cauldron. Preparation for war does, however, call for the services of chemists, and Mr. R. Brightman, who a little time ago discussed at Manchester the place of professional organisations in society, asks scientific workers to formulate a definite ethical code towards preparation for war. In a recent issue of The Chemical Practitioner he points out that so long as there is real risk of war, the fullest resources of science should be used to make warfare efficient, economical and unlikely, but that "while it might be accepted as part of the scientists' general code that research work in connexion with general war needs was always legitimate, it might equally be held that research on agencies prohibited by international agreement or participation in large scale production of armaments in peace time was illegitimate".

The trouble is that any such scheme, to be effective, would have to be universal; unilateral action might well be a disservice to the cause of peace. What is the chemist to reply if he is asked to help in arranging protection for the civil population against aerial gas attacks? Is he to point to the Geneva Protocol and hope for the best, or is he to allow his natural humanity to overcome his faith in human nature? This very subject of the education of the public in means for dealing with gas attacks was quite lately discussed before the British Science Guild by Mr. J. Davidson Pratt, the general manager of the Association of British Chemical Manufacturers.
The question of the scientific worker's duty in relation to the preservation of peace and to the provision of military necessities is obviously presenting doubts and difficulties to conscientious minds, which is all the more reason why the whole matter should receive earnest attention by professional organisations of scientific workers.

Mr. Ames truly says that if at any time the nation is drawn into a war the chemist's duty is the same as that of any other citizen; but that duty should not prevent him using his special powers and opportunities to strive with all his might against the warlike frame of mind and to harness the spirit of adventure to combat evils and distresses which familiarity almost persuades us to ignore. He finds the nobler adventure in a determined effort to provide work for everybody, and in doing so much he is doing more to undermine the causes of unrest.

Mr. Brightman thinks that scientific workers have come more and more to realise that, even in its narrowest sense, scientific or professional work is not something entirely apart from the life of society; that it cannot be truly isolated, and that it has to be integrated into the general life of the community. One of the ways in which this could be done more effectively would-as we have suggested before-be through the medium of the Press and of broadcasting. The social reformer gets ample opportunity for advocating his ideas for promoting the public advantage; his schemes for abolishing this and nationalising that. But the chemist (if we may take him as an example) speaks mostly through his own journals to his own people. It is necessary to impress on the public mind a picture of science in the making and science in application, to illustrate the aims, ideals and methods so familiar to the scientific worker but so little understood by the commercial public, to discuss the ways in which this new knowledge is being used, or might be used for the public good, and to examine with equal candour the possible repercussions which we would rather avoid. It is of no use trying to plan an unwilling State; nor will the State be willing until it understands a great deal more of the minds and the methods to be utilised. But it is learning by precept and by trial-and-error where organisation may usefully operate to the public profit, and where it still seems best not to limit individual freedom. The more it knowsnot about chemistry, for example, but about the part which chemists play in national life-the 
more will it be ready to listen to their advice; and the more chemists study the community, the more fit will they be to tender it.

Research workers cannot be a class apart in this modern world; they must mount the platform and advertise their wares. Individuals who have the ability as well as the knowledge can seek to use the popular Press as their tribuneand the Press will be willing enough if they attract readers; a science news service such as has been operating in the United States of America for some years past might be set up by a com- bination of professional organisations in Great Britain; and the universities might organise a comprehensive service in co-operation with the broadcasting authorities.

In any event, we shall not make the mistake of crying science as a panacea for all ills, for there are few of us who do not set great store by the preservation of moral and spiritual values; but we feel that in our scientific work we are carrying a responsibility which we cannot adequately discharge without public assistance in the widest and least mercenary sense of the term.

\section{The Foundations of Modern Science}

A History of Science, Technology and Philosophy in the I6th and 17 th Centuries

By Prof. A. Wolf, with the co-operation of Prof. Dr. F. Dannemann and A. Armitage. (History of Science Library.) Pp. xxvii $+693+68$ plates. (London: George Allen and Unwin, Ltd., 1935.) 25s. net.

THE book before us deals not only with pure science, but also with technology and philosophy. It is thus able to place science in a frame of other knowledge, and show the relations and cross-connexions between them. This method is desirable, indeed necessary, if a true appreciation of the picture is to be obtained. The early development of modern science was inevitably influenced by the philosophic environment in which it grew, and gained much by the gradual improvements in scientific implements, and by the problems thrust upon science by medicine and technology.

It will be seen how wide is the field which Prof. Wolf sets out to cover. It comprises several subjects not usually included in histories of, or treatises on, science-an extension which certainly adds to the interest of the whole. But this volume is but part of the scheme. In the preface we read :

"The present book is complete in itself. It is, however, intended to be only an instalment of a complete history of science. The author proposes to deal with the eighteenth and nineteenth centuries next, and then with ancient and mediæval times. But each volume will be as nearly as possible self-contained."

This extract serves to place Prof. Wolf's work between the encyclopædic "History of Science" of Dr. G. Sarton and the various specialised histories of particular branches of science on one hand, and single volume histories of science on the other.

The two centuries under review open with scholasticism still a power, though a waning power, in the intellectual world. Scholasticism reached its zenith in the thirteenth century, when the acute mind of St. Thomas Aquinas put together a logical, and within its limits, a complete scheme of existing knowledge, based on the Christian faith as interpreted by the Roman Church, and Nature as described by Aristotle. Accepting these two authorities, the scholastic philosophy seemed to the late Middle Ages to follow by deduction both logically and inevitably. This is what Whitehead means when he describes modern science, which is primarily inductive and not deductive, as "a recoil from the inflexible rationality of mediæval thought". Wolf criticises this pronouncement, saying that "due regard for the stubborn facts of observation is an essential part of any thoroughgoing rationality". Here, I think, he somewhat misunderstands Whitehead's meaning. But he is right in pointing out the influence of the Pythagorean emphasis on number in forming the thought of Copernicus and Kepler, though he seems to miss the point that this "earlier Greek tradition" persisted through the Middle Ages, first as the leading philosophy, and then as a survival, underlying, as an alternative, the prevailing late medieval Aristotelianism.

Although Aquinas himself was ready to consider the possibility of a moving earth, the geocentric theory, in the minds of lesser men, had become part of scholasticism. Thus the Copernican revolution was not only a simplification, and therefore a mathematical improvement, on the cycles and epicycles of Hipparchus and Ptolemy, but also a threat to reduce the earth, the home of man, 